\title{
High-resolution spatio-temporal analyses of drought episodes in the western Mediterranean basin (Spanish mainland, Iberian Peninsula)
}

\author{
J. C. González-Hidalgo ${ }^{1,2} \cdot$ S. M. Vicente-Serrano ${ }^{3} \cdot$ D. Peña-Angulo ${ }^{1,2} \cdot$ C. Salinas ${ }^{1,2} \cdot$ M. Tomas-Burguera $^{4} \cdot$ \\ S. Beguería ${ }^{4}$
}

Received: 27 October 2017 / Accepted: 30 March 2018/Published online: 6 April 2018

(c) The Author(s) 2018

\begin{abstract}
The purpose of this research was to identify major drought events on the Spanish mainland between 1961 and 2014 by means of two drought indices, and analyze the spatial propagation of drought conditions. The indices applied were the standardized precipitation index (SPI) and the standardized evaporation precipitation index (SPEI). The first was calculated as standardized anomalies of precipitation at various temporal intervals, while the second examined the climatic balance normalized at monthly scale, incorporating the relationship between precipitation and the atmospheric water demand. The daily meteorological data from Spanish Meteorological Archives (AEMet) were used in performing the analyses. Within the framework of the DESEMON project, original data were converted into a high spatial resolution grid $\left(1.1 \mathrm{~km}^{2}\right)$ following exhaustive quality control. Values of both indices were calculated on a weekly scale and different timescales (12, 24 and 36 months). The results show that during the first half of the study period, the SPI usually returned a higher identification of drought areas, while the reverse was true from the 1990s, suggesting that the effect from atmospheric evaporative demand could have increased. The temporal propagation from 12- to 24-month and 36-month timescales analyzed in the paper seems to be a far from straightforward phenomenon that does not follow a simple rule of time lag, because events at different temporal scales can overlap in time and space. Spatially, the propagation of drought events affecting more than $25 \%$ of the total land indicates the existence of various spatial gradients of drought propagation, mostly east-west or west-east, but also north-south have been found. No generalized episodes were found with a radial pattern, i.e., from inland to the coast.
\end{abstract}

Keywords Drought $\cdot$ SPI $\cdot$ SPEI $\cdot$ Spain $\cdot$ Spatial propagation

\section{Introduction}

Drought is one of the climate hazards that causes many negative impacts on natural and socioeconomic systems (Stahl et al. 2015, 2016; Van Loon et al. 2016). In addition,

J. C. González-Hidalgo

jcgh@unizar.es

1 Department of Geography, University of Zaragoza, Saragossa, Spain

2 IUCA, University of Zaragoza, Saragossa, Spain

3 Instituto Pirenaico de Ecología (IPE-CSIC), Saragossa, Spain

4 Estación Experimental Aula Dei (EEAD-CSIC), Saragossa, Spain drought analysis is not an easy task, as it is quite difficult to accurately determine the spatial and temporal dimensions of drought events (Wilhite and Glantz 1985; Lloyd-Hughes 2014; Vicente-Serrano 2016). For this reason, synthetic tools-the drought indices-have been developed, mostly based on the climate information (e.g., Heim 2002; Keyantash and Dracup 2002). These indices have been widely used to analyze the spatial and temporal behaviors of droughts (e.g., Van der Schrier et al. 2006) to identify drought impacts over a variety of sectors (e.g., Williams et al. 2013; Vicente-Serrano et al. 2013), and also to develop the bases for drought-monitoring systems worldwide (Svoboda et al. 2002).

In addition to uncertainties concerning problems caused by imprecise identification of the phenomenon, drought 
analyses face the problem of the scarcity of data available for detailed analysis (Seneviratne et al. 2012); therefore, because drought events are usually confined to a region (e.g., Soulé 1992; Lloyd-Hughes and Saunders 2002), studies using detailed spatial scales seem to be the best way to improve our knowledge on the behavior of the processes and associated impacts.

In the western Mediterranean basin and on the Spanish mainland, drought is a very frequent phenomenon, due to particular climate conditions. Different studies have identified ancient droughts by means of historical documents and different proxies (Domínguez-Castro et al. 2012; Tejedor et al. 2017), and during the instrumental period, several studies have also identified strong drought events during the last century (Vicente-Serrano 2006a). On the other hand, some studies have suggested that the Spanish mainland has witnessed an increased severity in droughts over the last few decades (Hoerling et al. 2012; VicenteSerrano et al. 2014a), causing heavy environmental, agricultural and economic impacts (e.g., Camarero et al. 2015; Pascoa et al. 2017). This suggests that drought management plans should be put in place to cope with the risk more efficiently (Maia and Vicente-Serrano 2017).

These studies offer a promising starting point for research into the recent behavior of drought on the Spanish mainland; however, it is unsafe to generalize their conclusions at sub-regional scales, mostly because data with low-spatial density was used, and also because an important feature of drought events is their strong spatial variability (Vicente-Serrano 2006a). Thus, several poorly understood questions on drought behavior on the Spanish mainland remain, significant among which is how droughts propagate in space and time. This is a crucial issue that receives scant analysis in the scientific literature.

In this study, we present a descriptive analysis of the major drought events on the Spanish mainland in recent decades, based on a high-resolution climate dataset. The objectives of the study are (i) to identify the major drought episodes, (ii) to compare the differences in drought identification between two drought indices: the standardized precipitation index (SPI), and the standardized precipitation evapotranspiration index (SPEI), and (iii) to identify spatial propagation gradients of major drought episodes.

\section{Data and methods}

A recent gridded drought index database was used, covering the whole Spain for the period 1961-2014 at the temporal resolution of 1 week and spatial resolution of $1.1 \mathrm{~km}^{2}$. The original dataset is based on the complete information digitalized from the archives of Spanish National Meteorological Agency (Agencia Estatal de
Meteorología, AEMet), and includes precipitation, air temperature, relative humidity, hours of sunshine and wind speed needed to calculate the Potential Evapotranspiration or atmospheric evaporative demand (AED). The AED was calculated by means of the FAO-56 Penman-Monteith equation (Allen et al. 1998). Details of the data processing, gridding and drought index calculation are given in Vicente-Serrano et al. (2017). The dataset can be found at http:// monitordesequia.csic.es.

The SPI and SPEI indices were calculated, which are two of the most widely used and recommended as drought indicators worldwide (WMO 2012); the standardized precipitation index (SPI) is based on precipitation data (McKee et al. 1993), and the standardized precipitation evapotranspiration index (SPEI) is based on the difference between precipitation and the AED (Vicente-Serrano et al. 2010), and includes a water balance. Therefore, by comparing both sets of results, the contribution of the AED on drought severity can be identified.

Major drought periods were defined using three criteria applied to the weekly time series of SPI and SPEI at a 12-month time lag: (i) a minimum duration of 3 weeks; (ii) the index threshold $<-1.28$ corresponding to return periods of 10 years, and represents an indication of drought severity; (iii) and drought conditions, as defined by index values, should affect more than $25 \%$ of the total Spanish mainland. Finally, to avoid over detection of periods, we included a new major episode when a minimum temporal lag of 3 weeks was found between well-identified drought episodes. In the present paper, our approach assumes stationary of the climatic conditions, which may not be the case, so the return periods should be taken with care. Although they are useful for spatial comparison as it is the purpose on this article, their validity as indicators of frequency of drought conditions does not hold under a climate change scenario.

Identification of the drought period focused on 12 months; we also analyzed 24 and 36 months timescales to determine time propagation, but only the 12-month results will be shown in detail. Droughts in Spain have very different dimensions, affecting agriculture, forests and the frequency of wild fires, but currently the most important impacts relate to the hydrological dimension, which may cause heavy losses in highly productive irrigated agriculture, reduce hydropower production, and cause problems for industry and the water supply (Jerez et al. 2013; Lorenzo-Lacruz et al. 2010, 2013). Due to dry summers and strong interannual variability of the climate in Spain, there is a very dense network of hydraulic infrastructures. Thus, after China, Spain has the second highest number of dams in the world, but the total surface area of the country is $5 \%$ that of China. The purpose of this dense network is to guarantee the water supply during the frequent drought 
periods. For this reason, hydrological droughts in Spain are not affected by short term droughts, usually identified on short SPI/SPEI timescales. Thus, the dense reservoir network even allows a noticeable reduction in the impact of annual drought events (12-month) on hydrological drought conditions. For example, the one affecting Spain in 2015 was the most severe since records began, but it did not cause hydrological droughts due to the large amount of hydraulic infrastructures. On the contrary, climate drought conditions recorded during 2-3 years, limit the capacity of infrastructures to cope with drought events, and cause problems for irrigation and water supply, as widely observed between 1992 and 1995. For these reasons, this paper focuses on long-term drought indices (12, 24 and 36 months), since they are really useful to assess the severity of hydrological droughts and determine how annual drought conditions can persist over longer timescales. Lorenzo-Lacruz et al. (2010) clearly illustrated how the multiannual large reservoirs, which are frequent and the basis for water management in Spain, are responding to very long drought timescales $>24$-month.

\section{Results}

\section{Major drought events on the Spanish mainland}

Table 1 shows the main drought periods identified for the Spanish mainland during the study on a 12-month timescale. Remember that identification of drought episodes combines duration, spatial effects and intensity, as described in Sect. "Data and methods". The table shows the start and end dates according to year, month and week, and includes the duration in weeks.

In the period analyzed, we identified a total of 15 major drought episodes in which at least $25 \%$ of land was under the drought conditions defined by an SPEI value of $<-1.28$. In general, both indices showed strong agreement in identifying the main drought periods between 1961 and 2014. Nevertheless, there are some differences regarding the start and end weeks of the drought episodes, and three episodes did not fulfill the requirements in SPI.

The duration of droughts also showed similar patterns, with the exception of the two main episodes identified at the end of the study period, when the SPEI detected drought conditions noticeably earlier and also provided an earlier end. Among the events identified with the SPEI, the most prolonged were recorded in 1989 (21 weeks), 1994-1995 (74 weeks), 1999 (27 weeks), 2005-2006 (56 weeks) and 2012 (38 weeks). The table also includes the main spatial propagation gradients (see below).

Comparison between SPI and SPEI is shown by the percentage of total land affected by droughts, including both thresholds $(<-0.28$, and $<-0.84$, with 10 - and 5 -year return period, respectively). Obviously, detection of the surface area differs as a function of the threshold, with the weakest ones being higher, but there were also some differences between SPI and SPEI for the three timescales

Table 1 Drought period identification (12-month scale) using SPEI and SPI threshold $(<-1.84)$

\begin{tabular}{|c|c|c|c|c|c|}
\hline Event & Spatial gradient propagation & SPEI & Duration & SPI & Duration \\
\hline 1 & W/E & 1965-Jun-3/1965-Sep-4 & 14 & 1965-Jul-2/1965-Sep-3 & 10 \\
\hline 2 & E/W & 1970-Dec-4/1971-Apr-2 & 15 & 1971-Jan-1/1971-Apr-1 & 13 \\
\hline 3 & $\mathrm{~W} / \mathrm{E}$ & 1981-Feb-3/1981-March-4 & 6 & 1981-Feb-3/1981-Dec-3 & $8+8+6+10$ \\
\hline 4 & W/E & 1981-Nov-1/1981-Dec-3 & 7 & & \\
\hline 5 & $\mathrm{E} / \mathrm{W}$ & 1983-Oct-3/1983-Dec-3 & $4+3$ & 1983-Sep-4/1983-Dec-2 & 11 \\
\hline 6 & $\mathrm{E} / \mathrm{W}$ & 1986-Мау-3/1986-Sep-2 & 16 & 1986-Jan-3/1986-Sep-1 & 15 \\
\hline 7 & $\mathrm{~N} / \mathrm{S}$ & 1989-Jun-3/1989-Nov-3 & 21 & 1989-Jun-2/1989-Nov-2 & $13+7$ \\
\hline 8 & W/E & 1992-Feb-1/1992-Jun-2 & 18 & 1992-Feb-1/1992-Jun-2 & 18 \\
\hline 9 & $\mathrm{E} / \mathrm{W}$ & 1994-Jan-3/1995-Dec-4 & 74 & 1994-Jan-1/1995-Dec-3 & 75 \\
\hline 10 & $\mathrm{E} / \mathrm{W}$ & 1999-Feb-1/1999-Feb-4 & 4 & 1999-Jan-4/1999-Oct-2 & $6+3+21$ \\
\hline 11 & $\mathrm{E} / \mathrm{W}$ & 1999-Apr-2/1999-Oct-2 & $2+21$ & & \\
\hline 12 & $\mathrm{E} / \mathrm{W}$ & 2002-Feb-4/2002-May-3 & $6+5$ & 2002-Feb-4/2002-May-4 & 13 \\
\hline 13 & $\mathrm{~W} / \mathrm{E}$ & 2005-March-4/2006-Jun-1 & $53+3$ & 2005-Apr-2/2006-Мау-2 & 45 \\
\hline 14 & $\mathrm{~W} / \mathrm{E}$ & 2009-Oct-2/2009-Dec-3 & 10 & / & \\
\hline 15 & N/S/NW/SE & 2012-Feb-3/2012-Dec-4 & $32+4+2$ & 2012-March-2/2012-Sep-3 & $4+1+1+16$ \\
\hline
\end{tabular}

Duration in weeks. Dates indicate start/end in monthly week

Duration expressed as $(+)$ indicates that between dates of event some weeks did not achieve the spatial threshold of $25 \%$ of total land. See text for explanation how to identify events 
analyzed (Fig. 1). The 12-month scale identified many drought periods affecting more than $25 \%$ of territory. It means that extended areas of the Spanish mainland were very frequently affected by drought conditions and is clearly related to the high interannual variability of rainfall in areas with a Mediterranean climate. On the other hand, on the 24- and 36-month scales, fewer episodes were found; nevertheless, some of these affected over $50 \%$ of the Spanish mainland, particularly from 1980, when extended areas under drought conditions were identified on 24- and 36-month scales. However, the relationship between timescales is far from simple: some episodes on the 12-month scale were not identified on the 24- or 36-month scales (see Fig. 1).

Figure 2 gives the comparison of percentage of total land affected by drought according to the SPEI and SPI, where the lines represent the difference in the percentage of surface area affected. Positive values indicate a larger area of drought according to the SPEI and vice versa. The different behavior between the two drought indices shows that since 2000, SPEI has progressively expanded identification of longer and more severe drought episodes than the SPI, and suggests that the role played by the AED could be
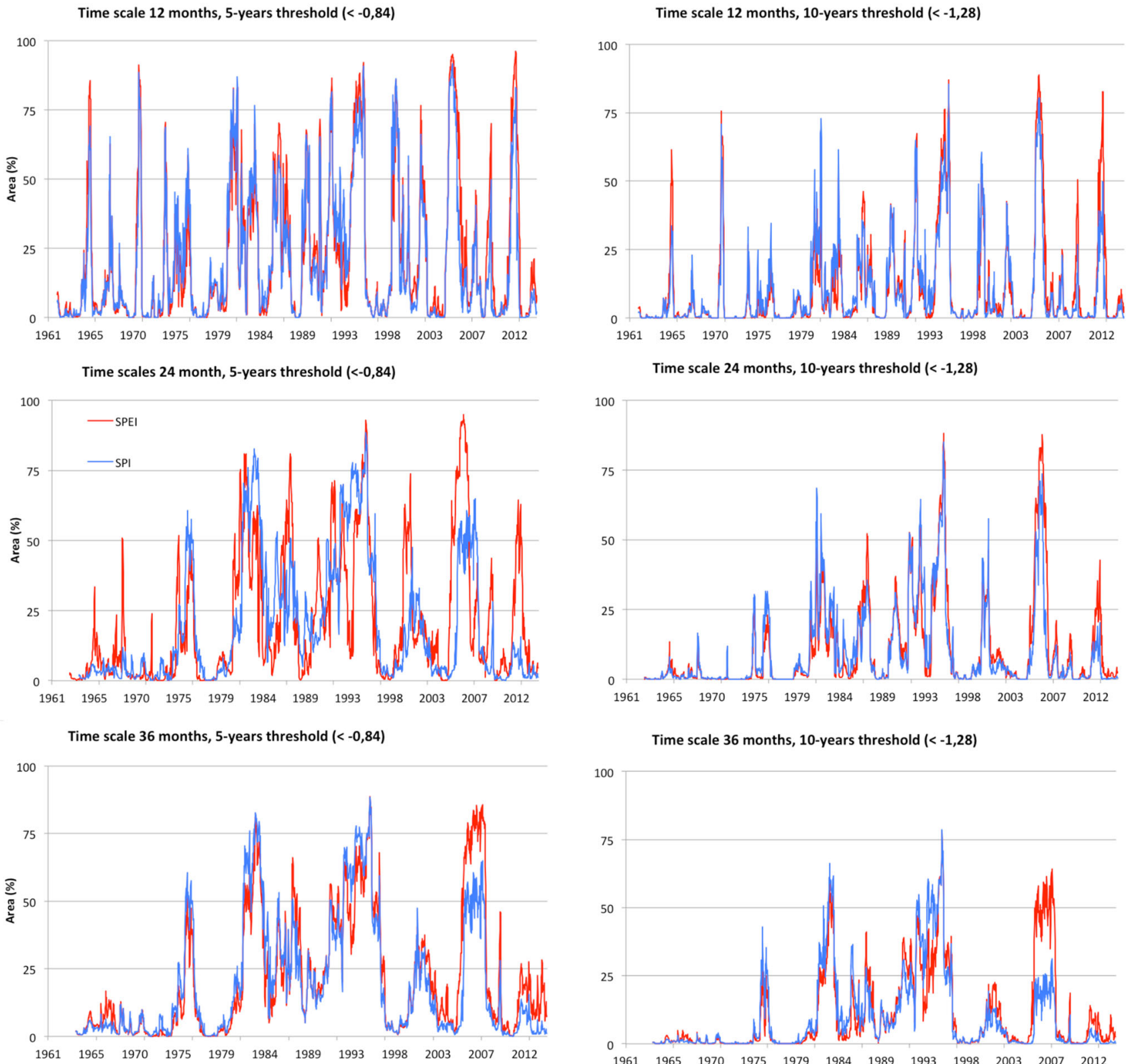
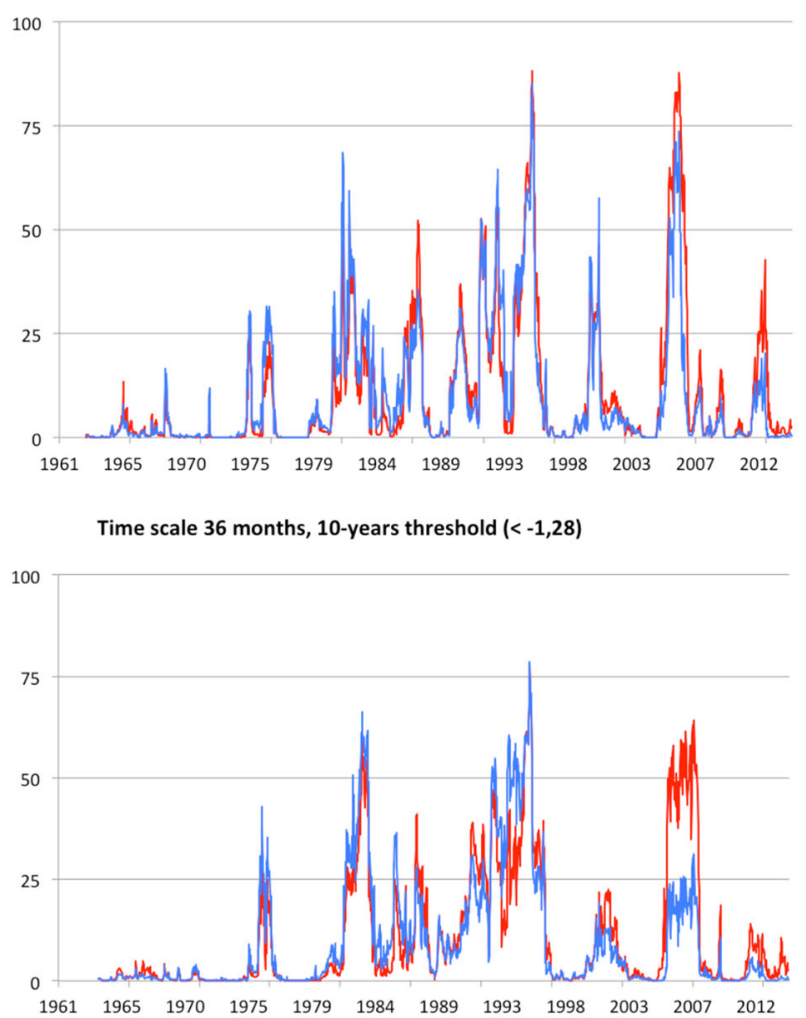

Fig. 1 Evolution of land affected (in \%) accordingly SPEI $(-)$ and SPI (-) at three temporal scales (12, 24 and 36 months) and two drought index thresholds $(<-1.28$ and $<-0.84)$ 
Fig. 2 Differences of land surface affected between SPEI and SPI at different times scales (12, 24 and 36 months). The values are accordingly (SPEISPI) percentage of land under $<-1.28$ threshold (10year return period)

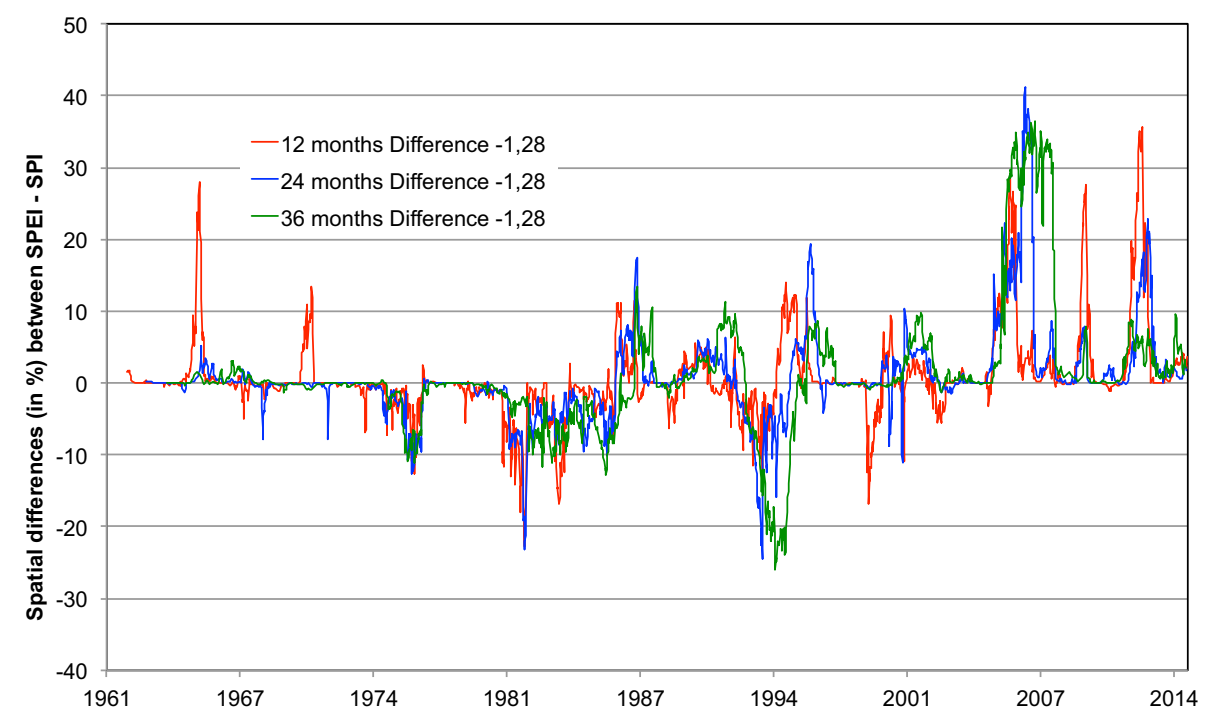

responsible for the increase in drought episodes on the Spanish mainland.

Filtering this information and isolating those events in which SPEI detected $>50 \%$ of Spanish mainland under the threshold of -1.28 (Fig. 1), led to a logical reduction in the number and length of drought events (data not shown). This suggests that some of the drought events identified in Table 1 (e.g., 1981, 1983, 1986, 1989, 2002 and 2009) may have depended more on factors controlling precipitation (see discussion).

These results suggest that drought events on the Spanish mainland can affect extensive areas, and second, the relationship between temporal scales varies greatly among episodes and does not follow a straightforward pattern. In some cases, the events detected on 12-month scales did not propagate to longer timescales (episodes first and second from Table 1, see Fig. 1). In other cases, the relationships were much more complex, and the temporal propagation of drought events detected at shorter (i.e., 12-month) to longer scales (i.e., 24 and 36 months) was combined with new drought episodes recorded at a shorter timescale. This caused an overlap in detection of drought episodes (see below). Figure 3 shows the evolution of areas (as a percentage) affected by drought conditions according to different timescales during events occurring between 1989 and 1995. The figure provides information on the relationship between the three temporal scales analyzed and shows how temporal lags in some cases are well recognized (continuous lines), but in others, there is an effect from overlapping episodes, or perhaps from temporal scales not analyzed in this paper (dashed lines).

\section{Spatial drought propagation}

The spatial propagation of major drought episodes was analyzed by examining the sequential chart of weekly SPEI and SPI indices. Three general spatial propagation gradients were identified during the analyzed period for the major drought episodes, with the two longitudinal (W-E and $\mathrm{E}-\mathrm{W}$ ) being more frequent than the latitudinal (mostly $\mathrm{N}-\mathrm{S}$ ). These gradients are indicated in Table 1 . The three spatial patterns were recognized in sequences of episodes between 1989 and 1995, during three successive events (numbers 7-9 on Table 1). The structure of this sequence, which may explain the total severity of the drought and also the complexity of drought analyses, was as follows:

\section{North-South gradient. Episode 7, from 1989-June 3 to 1989-November-3}

The areas affected by the defined threshold did not cover more than $50 \%$ of total land and the episode lasted for 21 weeks. This episode is the only one recorded in the dataset that shows a generalized north to south gradient, with clear asymmetry between the northern coastland and the Mediterranean region when the drought index returns positive values. The drought was particularly severe in November and the episode propagated to longer SPEI timescales in the expected temporal lag (Fig. 4).

\section{West-East gradient. Episode 8. 1992-February-1-1992- June-2}

The following episode was identified from 1992-February1 and 1992-June-2 on the 12-month timescale, lasting for 


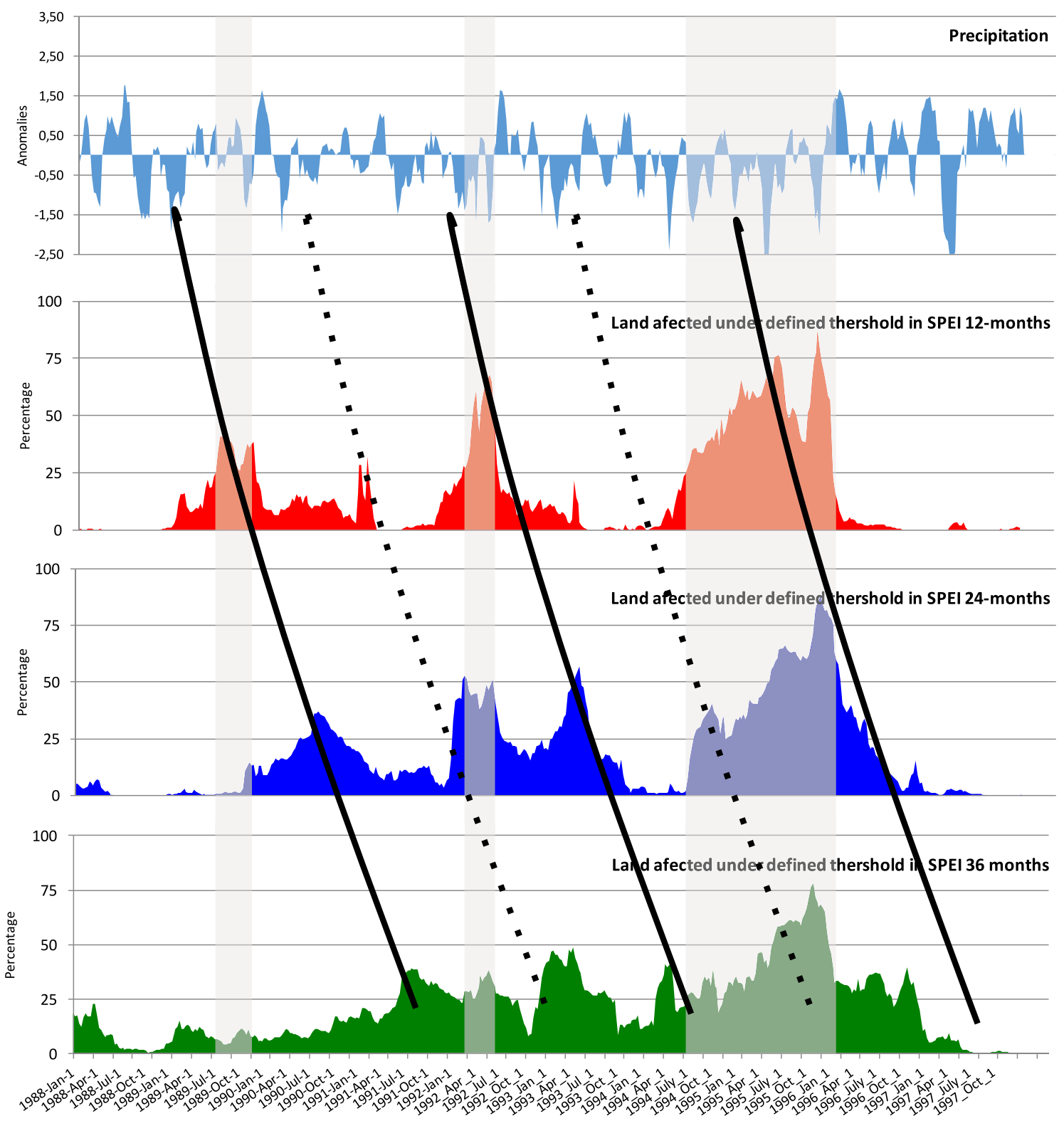

Fig. 3 The relationship between timescales in drought episodes. Figure shows from top to bottom (a) the precipitation, expressed as anomalies; (b) the percentage of land affected by defined threshold at 12 months; (c) at 24 months and (d) at 36 months, in the sequence of three episodes from 1989-June-3 to 1995-December-4 (from seventh to ninth episodes following Table 1). Slight shade (in vertical)

18 weeks. This episode overlapped the previous episode 7 of 1989, which did not recover at the 24- and 36-month timescales (see Fig. 3). For this reason, large areas affected by drought on the 12-month scale were also affected on the 24- and 36-month scales simultaneously, with more than $50 \%$ of total land under drought conditions. The spatial propagation of defined drought conditions on 12-month time-scales shows a clear gradient from west to east. Please indicates the duration of drought events. Continuous lines represent the relationships between monthly timescales, accordingly lags of 12-24-36 months for specific events identified at 12-month scale (see Table 1). Dashed lines indicate at 24 and 36 monthly scale episodes in which more than $25 \%$ of total land was under drought conditions not detected at 12-month scale

note that there is no data from Portugal to avoid misinterpretation of the spatial gradient from the Atlantic coast of the Iberian Peninsula. In the eastern Mediterranean coastal areas, no general drought severity was detected (Fig. 5). Finally, the proper 12-month drought event (number 8) was propagated at 24- and 36 months according to the expected lags. 


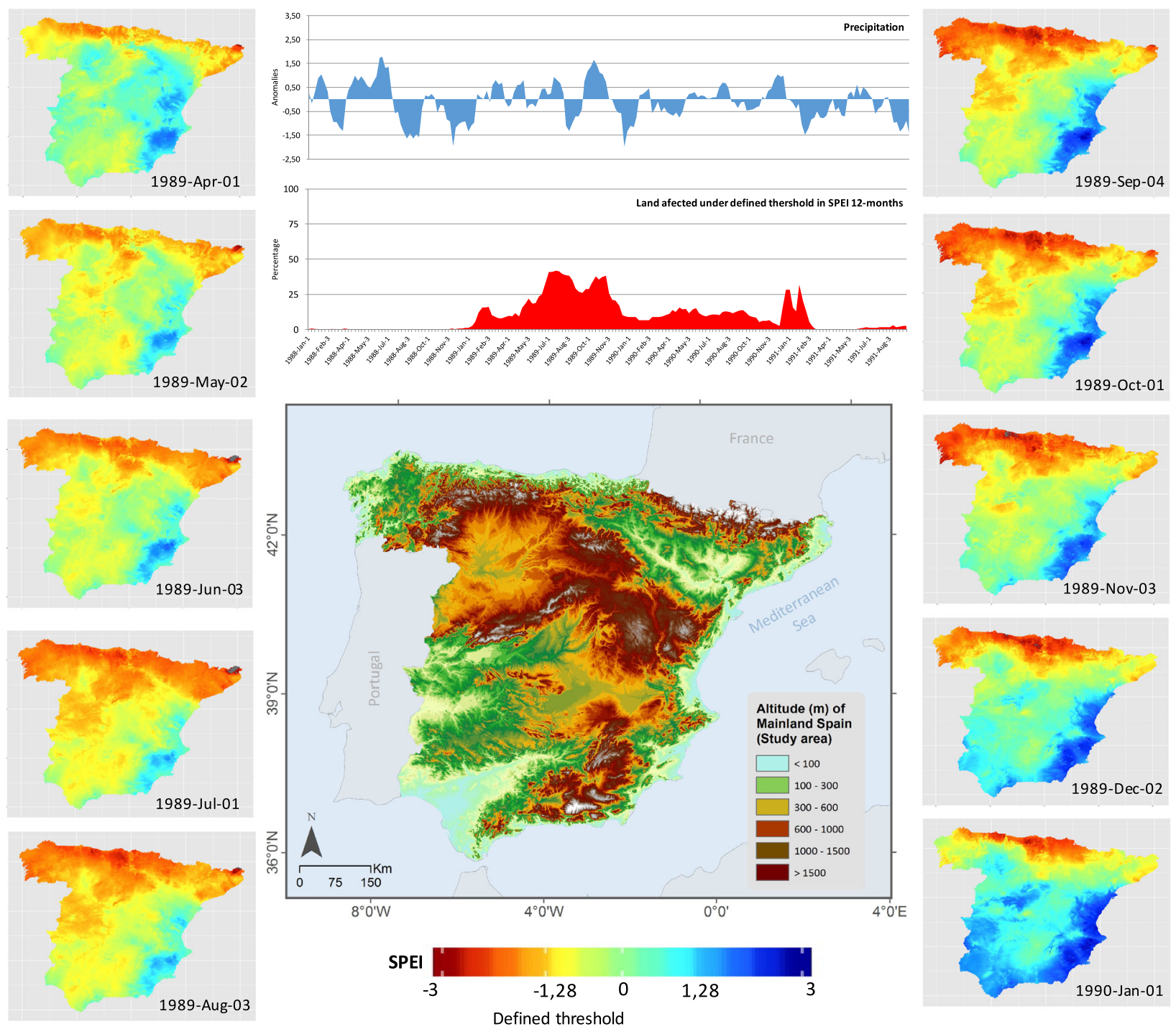

Fig. 4 Drought episodes from 1989-June-3 to 1989-November-3. The map collection shows the spatial evolution pattern (North-South) of SPEI values at selected weekly intervals

\section{East-West gradient. Episode 9. 1994-January-3-1995- December-4}

This sequence of drought periods finished with the longest episode recorded in the entire dataset. This ninth episode lasted for 74 weeks between June 1994 and December 1995. The new drought period identified on the 12-month timescale coincided with extended areas detected at 24 and 36 months relating to the previous episode, indicating a reactivation of the long-term drought conditions from the previous event. At the peak of highest severity, more than $85 \%$ of the Spanish mainland was under drought conditions on the 12- and 24-month timescales, and also more than $77 \%$ of the area was under drought conditions at 36-month SPEI in December 1995. This drought episode shows a clear gradient of propagation from east to west (Fig. 6).

\section{Discussion}

\section{General comments}

Droughts in Spain have very different dimensions, affecting agriculture, forests and the frequency of wild fires, but currently the most important impacts relate to the hydrological dimension, which may cause heavy losses in highly productive irrigated agriculture, reduce hydropower production, and cause problems for industry and the water supply (Jerez et al. 2013; Lorenzo-Lacruz et al. 2010, 2013). Due to dry summers and strong interannual variability of the climate in Spain, there is a very dense network of hydraulic infrastructures. Thus, after China, Spain has the second highest number of dams in the world, 


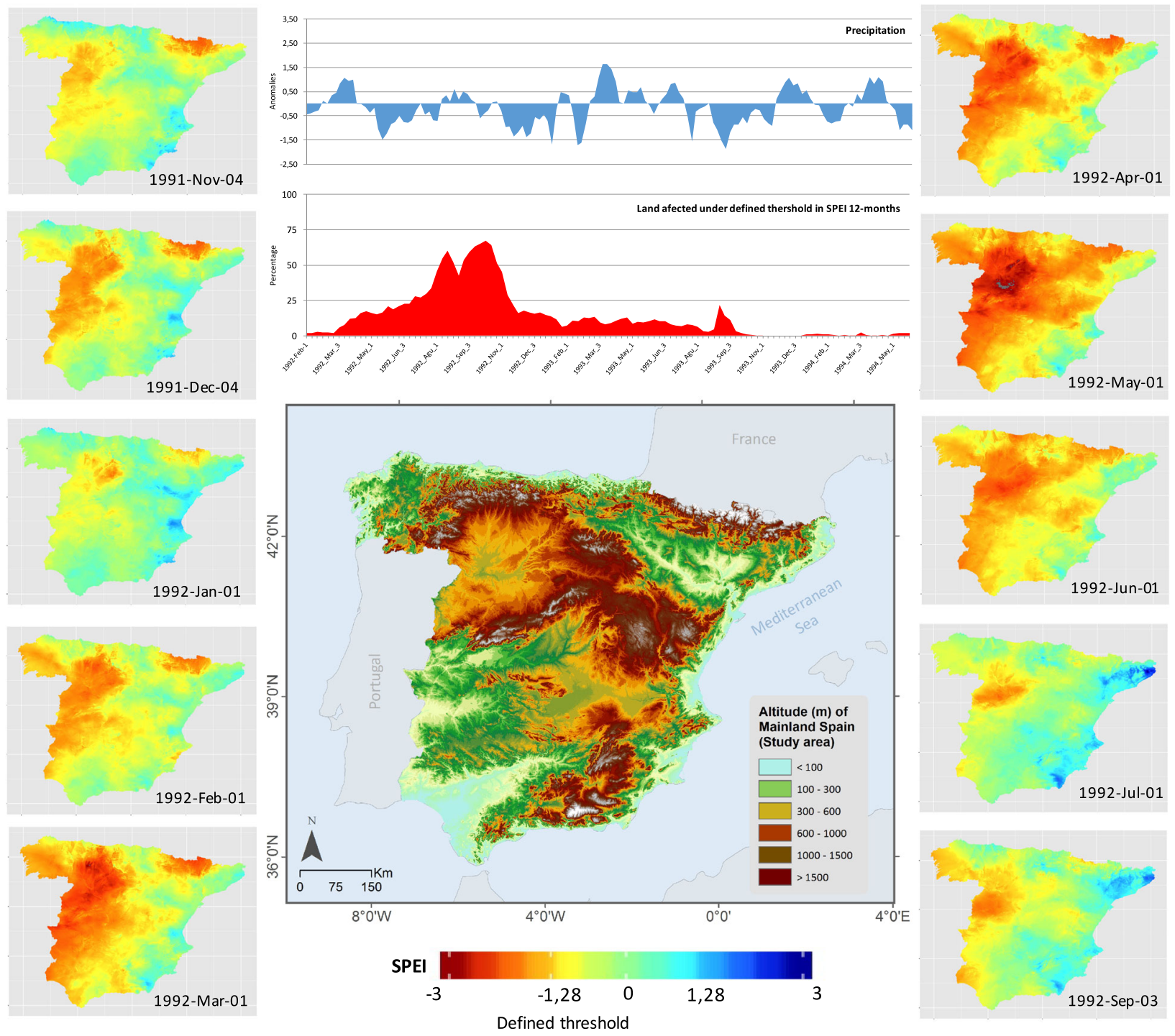

Fig. 5 Drought episode from 1992-February-1 to 1992-June-2. The map collection shows the spatial evolution pattern (West-East) of SPEI values at selected weekly intervals

but the total surface area of the country is 5\% that of China. The purpose of this dense network is to guarantee the water supply during the frequent drought periods. For this reason, hydrological droughts in Spain are not affected by short term droughts, usually identified on short SPI/SPEI timescales. Thus, the dense reservoir network even allows a noticeable reduction in the impact of annual drought events (12-month) on hydrological drought conditions. For example, the one affecting Spain in 2015 was the most severe since records began, but it did not cause hydrological droughts due to the large amount of hydraulic infrastructures. On the contrary, climate drought conditions recorded during 2-3 years, limit the capacity of infrastructures to cope with drought events, and cause problems for irrigation and water supply, as widely observed between 1992 and 1995. For these reasons, this paper focuses on long-term drought indices (12, 24 and 36 months), since they are really useful to assess the severity of hydrological droughts and determine how annual drought conditions can persist over longer timescales. Lorenzo-Lacruz et al. (2010) clearly illustrated how the multiannual large reservoirs, which are frequent and the basis for water management in Spain, are responding to very long drought timescales $>24-$ month.

Defining a drought period involves deciding which thresholds to use, and we focused on episodes covering the largest surface areas under defined drought thresholds. This meant that some minor drought periods (regional to local) were not identified in this study, but there is evidence proving that they are frequent on the Spanish mainland (Vicente-Serrano et al. 2014; Peña-Gallardo et al. 2016). We hope in future to be able to analyze all drought periods 


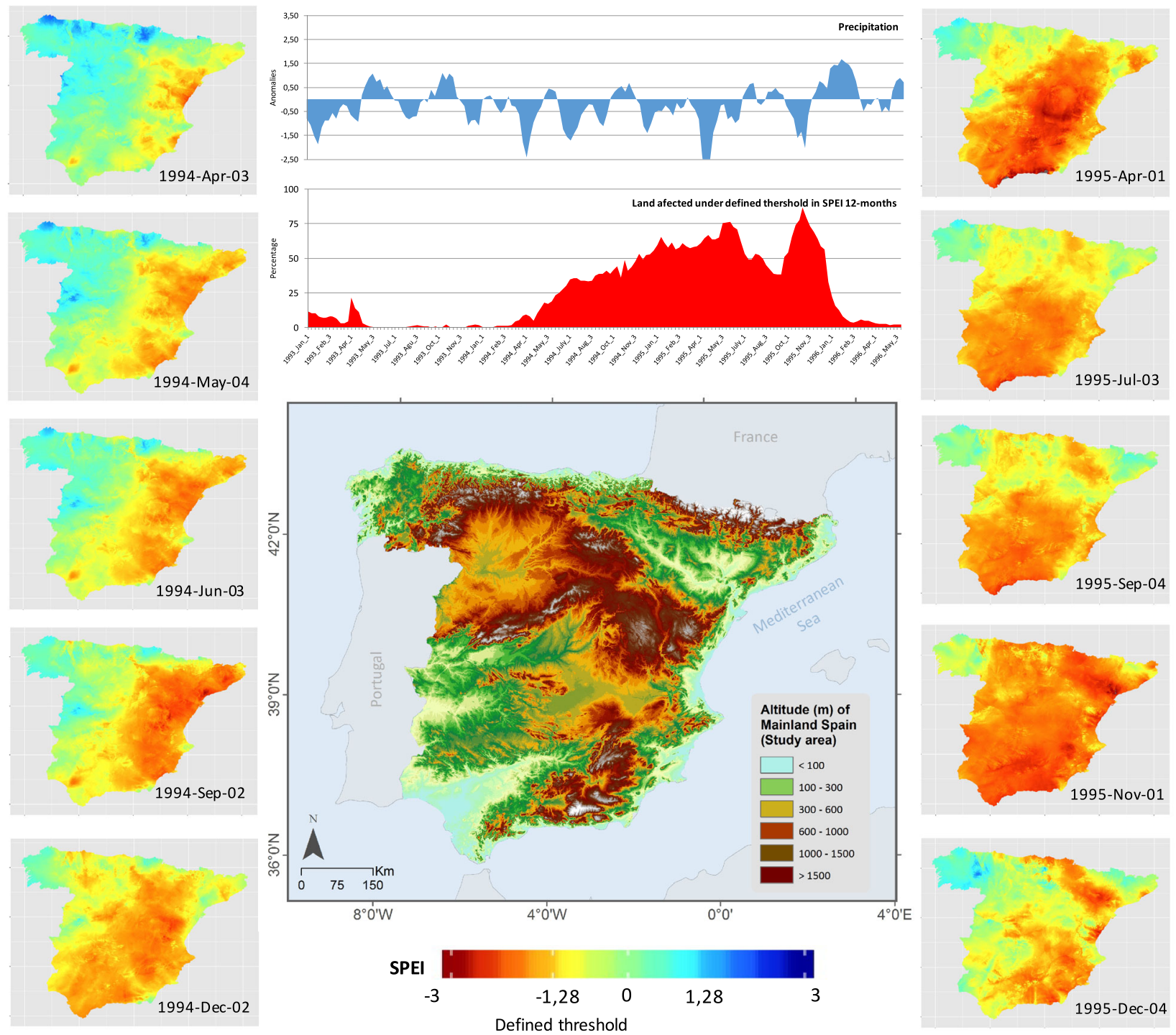

Fig. 6 Drought episode from 1994-June-3 to 1995-December-4. The map collection shows the spatial evolution pattern bottom (East-West) of SPEI values at selected weekly intervals

affecting the Spanish mainland to develop a drought catalog. In the meantime, this research shows that when identifying outstanding global drought events, the use of thresholds based on the drought index combined with the surface area affected by droughts are an interesting tool, even though they are insufficient to determine the real severity of these events at sub-regional scales. The use of different timescales is equally important for this purpose. Nevertheless, this is a difficult task, since a simple assumption of temporal propagation of the drought conditions across different timescales is not so simple, as illustrated in this paper, for events between 1989 and 1995. In summary, individual drought events must be put in a temporal context because in many circumstances they are promoted or exacerbated by past conditions.
In this study, we identified "simple" major drought episodes on a timescale of 12 months. These are the less complex droughts analyzed, and in general, they were found at the beginning of the study period. This became more complex when seeking to extend 12-month drought episodes to 24- and 36-month scales, when we detected overlapping effects at times. In these episodes, the eventual propagation from shorter to longer timescales is much more difficult to detect, since the drought conditions are not clearly identified at shorter timescales. This would be much more complex if shorter $(<12$-month) and longer (> 36-month) scales were incorporated. In short, a drought episode must be understood according to its temporal context and never analyzed as an isolated feature. 


\section{Differences between drought indices}

There is a progressively divergent evolution of the percentage of land affected by drought conditions defined by two different drought indices for the Spanish mainland. Given the diverse nature of the indices, it suggests that the triggering factors driving droughts on the Spanish mainland may have changed during the last few decades.

Various studies have suggested a possible role of global warming on drought severity on the global scale (e.g., Trenberth et al. 2014) following intensification of the hydrological cycle as a consequence of increased AED (Huntington 2006). Nevertheless, the uncertain availability of data is a serious drawback, and prevents a general conclusion being drawn on this issue on a global scale (Seneviratne et al. 2012). In this paper, we sought to avoid these constraints in our regional analyses of drought on the Spanish mainland using a high-resolution spatial dataset, and the main results suggest that the surface affected by droughts in the last two decades may be caused by different mechanisms from previous ones.

We found that the area detected under drought conditions prior to c. 1990 usually has a higher SPI than SPEI indicator. This result suggests that prior to 1990, droughts were mostly related to changes in precipitation, and after 1990 that, in addition to the role of precipitation variability, the atmospheric evaporative demand (AED) has acted as drought triggering factor. These results are coherent with temperature and precipitation evolution on the Spanish mainland, where the most recent studies have detected a general temperature increase from 1951 to 2010, particularly between 1970 and 1990, mostly affecting the spring and summer minimum records (Gonzalez-Hidalgo et al. $2015,2017)$, while no significant trend in precipitation was found except for March and June (negative and significant) between 1946 and 2005, and particularly from 1970 (Gonzalez-Hidalgo et al. 2011); the results have been confirmed and updated to 2015 by Notivoli (2017). Furthermore, recent evaluation of AED on the Spanish mainland suggested a global increase of about $125 \mathrm{~mm}$ since 1960 , which has been attributed to the increase in vapor pressure deficit (Vicente-Serrano et al. 2014b). These findings agree with the results of higher drought detection by SPEI than SPI in the last two decades, and suggest that the water supply to the atmosphere has not been sufficient to cope with the water demand, in line with the warming observed (Vicente-Serrano et al. 2014c). In brief, the global drought framework has recently been driven by new temperature conditions that control AED, irrespective of the evolution of precipitation.

\section{Drought event propagation processes}

Spatial variability of drought events is highly complex on a regional scale. This has been demonstrated in several regions of the world (e.g., Skaggs 1975; Song et al. 2014; Capra and Scicolone 2012), and also in previous analyses in the Iberian Peninsula (Vicente-Serrano 2006b) where it has been suggested that spatial drought patterns may differ as a function of the timescale of the drought index, and longer timescales may give rise to more diverse patterns, given the longer impact of the specific local precipitation events.

In the present study, we confirmed these previous findings at high-resolution level, but the results go further and show that there are different spatial gradients of drought propagation.

On mainland Spain, we found three spatial drought propagation gradients that could be linked to several factors controlling droughts. Various explanations have been suggested for precipitation and temperature evolution linked to global and local factors (e.g., Gonzalez-Hidalgo et al. 2011, 2017), in which different hemispheric circulation mechanisms, or more local ones, such as land use changes, have been suggested. Regardless of the exact reason, which is not the objective of this paper, we found that the onset of main drought episodes followed a coastinland gradient, and no episodes were identified from inland to the coast. It is highly probable that this relates to the main sources of moisture from the Atlantic or Mediterranean water masses (Gimeno et al. 2010), and suggests that the low value of convective rainfalls on annual total precipitation, mostly produced in summer and highly irregular, thus with little effect on both drought indices.

The spatial propagation of droughts also shows the effect caused by the main relief features in the spatial distribution of affected areas, and resembles the wellknown spatial areas affected by the most prominent teleconnection patterns. Thus, under west-east propagation episodes, the mountains act as a frontier separating the central-western Spanish conterminous land under drought conditions from the Mediterranean coastland that may be under moist conditions. These features closely resemble the spatial distribution of the North Atlantic Oscillation effects on precipitation and temperature, particularly during the Winter months. Under east-west propagation episodes, the same is true in the opposite direction, and resemble the areas affected by the Western Mediterranean Oscillation. This mountain border effect is more evident when the affected areas are less than $25 \%$ of total land (not analyzed in the present paper), but clearly recognized in the case of 
1979-1980 episodes in the Mediterranean coastland (not presented).

The third most significant results concern the onset of drought. Apparently, drought episodes start at two different times: (i) the cold months from autumn (1971, 1981, 1994 and 1995), and (ii) the end of winter or beginning of spring (1965, 1992, 2005 and 2012). The differences in the onset of droughts would be able to explain the behavior of the event, and the differences found in the SPI and SPEI. In the first case, when drought starts at the end of autumn it seems to suggest that the previous summer avoided drought conditions by spring-summer precipitation delayed to the beginning of autumn, notwithstanding the positive significant trend of precipitation in October, this should be taken into account in future detailed research. In the second case, when drought starts at the end of winter, it seems to be related with scant winter precipitation. In brief, we can conclude that there are different types of drought, depending on their origin, sometimes promoted by scarce rainfall (the first case), or by means of a more complex mechanism combining low rainfall and the different factors controlling AED.

These findings could be the reason lying behind divergence in surface detection by SPI and SPEI, and also how drought spreads differently according to different temporal scales.

To conclude, the high-resolution analyses of drought on both scales, spatial and temporal, in the Spanish conterminous land indicates the extreme complexity of the phenomenon, the need for further research, and caution when extrapolating from general conclusions.

Acknowledgements This work is supported by the projects CGL2014-52135-C03-01, CGL2014-52135-C3-3-R and PCIN-2015220, financed by the Spanish Government, Ministry of the Economy and Finance and FEDER, IMDROFLOOD financed by the Water Works 2014 co-funded call of the European Commission, INDECIS, financed by the ERA-NET Cofund for Climate Services of the European Research Area for Climate Services, and the Regional Government of Aragón DGA-FSE (Grupo de Investigación Consolidado 'Clima, Agua, Cambio Global y Sistemas Naturales'). Celia Salinas is a FPI-PhD student supported by the Ministry of the Economy and Finance. Miquel Tomas-Burguera was supported by the predoctoral FPU program 2013 (Ministry of Education, Culture and Sport). Original data from AEMet.

Open Access This article is distributed under the terms of the Creative Commons Attribution 4.0 International License (http://creative commons.org/licenses/by/4.0/), which permits unrestricted use, distribution, and reproduction in any medium, provided you give appropriate credit to the original author(s) and the source, provide a link to the Creative Commons license, and indicate if changes were made.

\section{References}

Allen RG, Pereira LS, Raes D, Smith M (1998) Crop evapotranspiration: guidelines for computing crop requirements, irrigation and drainage paper 56. FAO, Roma
Camarero JJ, Gazol A, Sangüesa-Barreda G, Oliva J, Vicente-Serrano SM (2015) To die or not to die: early warnings of tree dieback in response to a severe drought. J Ecol 103:44-57

Capra A, Scicolone B (2012) Spatiotemporal variability of drought on a short-medium timescale in the Calabria region (Southern Italy). Theor Appl Climatol 116:371-384

Domínguez-Castro F, Ribera P, García-Herrera R et al (2012) Assessing extreme droughts in Spain during 1750-1850 from rogation ceremonies. Clim Past 8:705-722

Gimeno L, Nieto R, Trigo RM, Vicente-Serrano SM, López-Moreno JI (2010) Where does the Iberian Peninsula moisture come from? An answer based on a Lagrangian approach. J Hydrometeorol 11:421-436

Gonzalez-Hidalgo JC, Brunetti M, de Luis M (2011) A new tool for monthly precipitation analysis in Spain: MOPREDAS database (Monthly precipitation trends December 1945-November 2005). Int J Climatol 31:715-731

Gonzalez-Hidalgo JC, Peña-Angulo D, Brunetti M, Cortesi C (2015) MOTEDAS: a new monthly temperature database for mainland Spain and the trend in temperature (1951-2010). Int J Climatol 35:4444-4463. https://doi.org/10.1002/joc.4298

Gonzalez-Hidalgo JC, Peña-Angulo D, Salinas-Solé C, Brunetti M (2017) A moving windows visual approach to analyze spatial variation of temperature trends in spanish mainland 1951-2010. Int J Climatol. https://doi.org/10.1002/joc.5288

Heim RR (2002) A review of twentieth-century drought indices used in the United States. BAMS 83:1149-1165

Hoerling $\mathrm{M}$ et al (2012) On the increased frequency of Mediterranean drought. J Clim 25:2146-2161

Huntington TG (2006) Evidence for intensification of the global water cycle: review and synthesis. J Hydrol 319:83-95

Jerez S, Trigo RM, Vicente-Serrano SM, Pozo-Vazquez D, LorentePlazas R, Lorenzo-Lacruz J, Santos-Alamillos F, Montavez JP (2013) The impact of the North Atlantic Oscillation on renewable energy resources in Southwestern Europe. J Appl Meteorol Climatol 52:2204-2225

Keyantash J, Dracup J (2002) The quantification of drought: an evaluation of drought indices. BAMS 83:1167-1180

Lloyd-Hughes B (2014) The impracticality of a universal drought definition. Theor Appl Climatol 117:607-611

Lloyd-Hughes B, Saunders MA (2002) A drought climatology for Europe. Int J Climatol 22:1571-1592

Lorenzo-Lacruz J, Vicente-Serrano SM, Lopez-Moreno JI, Begueria S, Garcia-Ruiz JM, Cuadrat JM (2010) The impact of droughts and water management on various hydrological systems in the headwaters of the Tagus River (central Spain). J Hydrol 386:13-26

Lorenzo-Lacruz J, Vicente S, González-Hidalgo JC, López-Moreno JI, Cortesi N (2013) Hydrological drought response to meteorological drought in the Iberian Peninsula. Clim Res 58:117-131

Maia R, Vicente-Serrano SM (2017) Drought planning and management in the Iberian Peninsula. In: Wilhite D, Pulwarty ES (eds) Drought and water crises: science, technology and management issues. CRC, Boca Raton

McKee TBN, Doesken J, Kleist J (1993) The relationship of drought frequency and duration to timescales. In: Proceedings of the Eighth Conference on Applied Climatology. American Meteorological Society, Boston, pp 179-184

Pascoa P, Gouveia CM, Russo A, Trigo RM (2017) The role of drought on wheat yield interannual variability in the Iberian Peninsula from 1929 to 2012. Int J Biometeorol 61:439-451. https://doi.org/10.1007/s00484-016-1224-X

Peña-Gallardo M, Gámiz-Fortís SR, Castro-Diez Y, Esteban-Parra MJ (2016) Comparative analysis of drought indices in Andalusia during the period 1901-2012. Cuadernos de Investigacion Geográfica 42:67-88 
Seneviratne SI, Nicholls N, Easterling D, Goodess CM et al (2012). Changes in climate extremes and their impacts on the natural physical environment. In: Field CB, Barros V, Stocker TF, et al (eds) Managing the risks of extreme events and disasters to advance climate change adaptation . A Special Report of Working Groups I and II of the Intergovernmental Panel on Climate Change (IPCC). Cambridge University Press, Cambridge, UK, and New York, NY, USA, pp 109-230

Serrano-Notivoli Roberto (2017) Reconstrucción climática instrumental a escala diaria en España y análisis de extremos. $\mathrm{PhD}$ Thesis, University of Zaragoza, Spain

Skaggs RH (1975) Drought in the united states, 1931-40. Ann Assoc Am Geogr 65:391-402

Song X, Li L, Fu G et al (2014) Spatial-temporal variations of spring drought based on spring-composite index values for the Songnen Plain, Northeast China. Theor Appl Climatol 110:471-488

Soulé PT (1992) Spatial patterns of drought frequency and duration in the contiguous USA based on multiple drought event definitions. Int J Climatol 12:11-24

Stahl K, Kohn I, De Stefano L et al (2015) An impact perspective on pan-European drought sensitivity. Drought: Research and Science-Policy Interfacing. In: Proceedings of the International Conference on Drought: Research and Science-Policy Interfacing, pp 329-334

Stahl K, Kohn I, Blauhut V et al (2016) Impacts of European drought events: insights from an international database of text-based reports. Nat Hazards Earth Syst Sci 16:801-819

Svoboda M, LeComte D, Hayes M, Heim R, Gleason K, Angel J, Rippey B, Tinker R, Palecki M, Stooksbury D, Miskus D, Stephens S (2002) The drought monitor. BAMS 83:1181-1190

Tejedor E, Saz MA, Esper J et al (2017) Summer drought reconstruction in northeastern Spain inferred from a tree ring latewood network since 1734. Geophys Res Lett 44:8492-8500

Trenberth $\mathrm{K}$ et al (2014) Global warming and changes in drought: expectations, observations and uncertainties. Nat Clim Change $4: 17-22$

van der Schrier G, Briffa KR, Jones PD, Osborn TJ (2006) Summer moisture variability across Europe. J Clim 19:2818-2834

Van Loon AF, Gleeson T, Clark J et al (2016) Drought in the Anthropocene. Nat Geosci 9:89-91
Vicente-Serrano SM (2006a) Spatial and temporal analysis of droughts in the Iberian Peninsula (1910-2000). Hydrol Sci J 51:83-97

Vicente-Serrano SM (2006b) Differences in spatial patterns of drought on different timescales: an analysis of the Iberian Peninsula. Water Resour Manage 20:37-60

Vicente-Serrano SM (2016) Foreword: drought complexity and assessment under climate change conditions. Cuadernos de Investigación Geográfica 42:7-11

Vicente Serrano SM, González-Hidalgo JC, de Luis M, Raventós J (2004) Spatial and temporal patterns of droughts in the Mediterranean area: the Valencia region (East-Spain). Clim Res 26:5-15

Vicente-Serrano SM, Beguería S, López-Moreno JI (2010) A multiscalar drought index sensitive to global warming: the standardized precipitation evapotranspiration index. J Clim 23:1696-1718

Vicente-Serrano SM, Gouveia C, Camarero JJ et al (2013) The response of vegetation to drought time-scales across global land biomes. Proc Natl Acad Sci USA 110:52-57

Vicente-Serrano SM, Lopez-Moreno JI, Beguería S et al (2014a) Evidence of increasing drought severity caused by temperature rise in southern Europe. Environ Res Lett 9:044001. https://doi. org/10.1088/1748-9326/9/4/044001

Vicente-Serrano SM, Azorin-Molina C, Sanchez-Lorenzo A et al (2014b) Reference evapotranspiration variability and trends in Spain, 1961-2011. Glob Planet Change 121:26-40

Vicente-Serrano SM, Azorin-Molina C, Sanchez-Lorenzo A et al (2014c) Sensitivity of reference evapotranspiration to changes in meteorological parameters in Spain (1961-2011). Water Resour Res 50:8458-8480

Vicente-Serrano SM, Tomas-Burguera M, Beguería S et al (2017) A high resolution dataset of drought indices for Spain. Data 2:22. https://doi.org/10.3390/data2030022

Wilhite DA, Glantz MH (1985) Understanding the drought phenomenon: the role of definitions. Water Int 10:111-120

Williams AP, Allen CD, Macalady AK et al (2013) Temperature as a potent driver of regional forest drought stress and tree mortality. Nat Clim Change 3:292-297

World Meteorological Organization (2012) Standardized Precipitation Index User Guide (M. Svoboda, M. Hayes and D. Wood). (WMO-No. 1090), Geneva 